\title{
O PAPEL DA CONEXÃO AFETIVA NA CONSTRUÇÃO DE UM PROGRAMA DE INTERVENÇÃO PRECOCE PARA CRIANÇAS RECÉM-DIAGNOSTICADAS AUTISTAS OU COM RISCO AUTÍSTICO
}

Olivia Balster Fiore Correia

De acordo com a abordagem desenvolvimentista, falhas inatas na capacidade de conexão afetiva das crianças autistas com as pessoas ocasionam prejuízos em suas interaçôes sociais e um desvio em seu desenvolvimento. Intervenções precoces que seguem esta abordagem procuram sanar ou amenizar estes prejuízos, de modo que estas crianças possam se desenvolver o mais tipicamente possível. O objetivo da pesquisa foi construir um programa de intervenção precoce que desenvolvesse os comportamentos do desenvolvimento infantil típico em crianças autistas, através do fomento da conexão afetiva das crianças nas interações sociais. Participaram cinco crianças autistas, entre os três e quatro anos, e os seus cuidadores. O programa mostrou-se eficaz, pois todas as crianças desenvolveram conexão afetiva, interações sociais e comportamentos, com ressalvas em relação ao grau de conexão afetiva, interações e comportamentos conseguidos em cada criança.

\section{BANCA:}

Carolina Lampreia (Orientadora)

Flavia Sollero de Campos

Heloisa Helena Alves Brasil

Maria Inês Garcia de Freitas Bittencourt

Maryse Helena Felipe de Oliveira Suplino

Data da defesa: 24/03/2010 